Bài báo khoa học

\title{
Nghiên cứu thử nghiệm phương pháp theo dõi quỹ đạo dông sử dụng dữ liệu ra đa thời tiết tại Việt Nam
}

\section{Bùi Thị Khánh Hoà ${ }^{*}$, Nguyễn Vinh Thư ${ }^{1}$, Phùng Kiến Quốc ${ }^{1}$, Nguyễn Việt Hưng ${ }^{1}$, Nguyễn Thị Hoàng Anh ${ }^{1}$}

${ }^{1}$ Đài Khí tượng cao không; khanhhoa303@gmail.com; vinhthu73@gmail.com; kienquocamo@gmail.com; nguyenviethungb115@gmail.com; hoanganhck@gmail.com

* Tác giả liên hệ: khanhhoa303@gmail.com; Tel.: +84-916591270

Ban Biên tập nhận bài: 29/1/2021; Ngày phản biện xong: 18/3/2021; Ngày đăng bài: $25 / 4 / 2021$

Tóm tắt: Ra đa thời tiết là công cụ quan trắc phục vụ đắc lực cho việc theo dõi, phát hiện và dự báo sự di chuyển của các vùng mây đối lưu có khả năng gây các hiện tượng thời tiết nguy hiểm. Bài báo này giới thiệu phương pháp mới theo dõi quỹ đạo di chuyển của vùng mưa dông được phát triển dựa trên phần mềm TITAN "Thunderstorm identification, tracking, analysis and nowcasting" có sử dụng thông tin phản hồi vô tuyến của ra đa ở Việt Nam. Nghiên cứu thử nghiệm áp dụng cho trường hợp mưa dông ngày 23/9/2020 tại khu vực Tây Bắc và cơn dông gây mưa cục bộ cho tỉnh Kon Tum và Đăk Nông ngày 27/2/2021. Kết quả chỉ ra rằng thuật toán được phát triển để theo dõi quỹ đạo di chuyển của vùng mưa dông là tương đối phù hợp và nắm bắt được $x u$ hướng dịch chuyển của các vùng mây từ khi xuất hiện đến khi tan rã. Tuy nhiên dường như thuật toán phù hợp hơn với việc theo dõi các ổ dông đơn lẻ.

Từ khóa: Mưa dông; Ra đa thời tiết; Quỹ đạo.

\section{Mở đầu}

Các hệ thống thời tiết đối lưu như mưa đá, dông lốc và lốc xoáy có thể gây thiệt hại nghiêm trọng đến sản xuất và đời sống hàng ngày. Vì vậy việc nâng cao khả năng dự báo thời tiết đối lưu và đưa ra được các cảnh báo thiết thực để giảm thiểu thiệt hại là rất có ý nghĩa. Với độ phân giải không gian và thời gian cao, hệ thống ra đa thời tiết hiện đại có thể cung cấp nhiều thông tin như phản hồi vô tuyến (PHVT), vận tốc xuyên tâm, độ rộng phổ,... đã trở thành công cụ quan trắc phục vụ đắc lực cho công tác dự báo thời tiết hiện nay. Việc nhận dạng và giám sát dông bão thông qua hệ thống ra đa thời tiết và công nghệ máy tính trở thành một kỹ thuật quan trọng để cảnh báo thời tiết khắc nghiệt. Tuy nhiên, việc dự báo quỹ đạo dông là rất khó, đặc biệt là ở các vùng nhiệt đới vì đa phần dông có kích thước nhỏ, biến động mạnh và tồn tại trong thời gian ngắn.

PHVT của ra đa thời tiết là thông số phổ biến nhất trong việc xác định dông bão. Các nghiên cứu về xác định, theo dõi và dự báo dông sử dụng PHVT của ra đa thời tiết đã diễn ra trong nhiều thập kỷ qua [1-11]. Cách tiếp cận đơn giản nhất để xác định các cơn dông là xác định ngưỡng hình ảnh dựa trên giá trị PHVT hợp lý về mặt vật lý. Hai phương pháp nổi tiếng để xác định, theo dõi, phân tích và dự báo dông bão là TITAN (Thunderstorm Identification, Tracking, Analysis and Nowcasting) [1] và xác định - theo dõi ổ mây dông là SCIT (Storm Cell Identification and Tracking) [5]. TITAN là một thuật toán dự báo kiểu centroid có thể xác định, theo dõi và dự báo hiệu quả các ổ dông đối lưu riêng lẻ nhưng TITAN có xu hướng cung cấp thông tin nhận dạng, theo dõi và dự báo chưa chính xác trong trường hợp các ổ dông 
dày đặc có hình dạng thay đổi nhanh chóng hoặc nơi các cụm ổ dông thường xuyên xảy ra. Thuật toán TITAN ban đầu sử dụng một ngưỡng duy nhất để xác định các ổ dông. Sau đó, các ổ dông này được theo dõi qua các lần quét ra đa liên tiếp bằng cách sử dụng phương pháp tối ưu hóa tổ hợp cùng với thuật toán bổ sung để xử lý các chuyển động bất thường của dông như phân tách hoặc hợp nhất. Thuật toán SCIT được phát triển để xác định, mô tả đặc điểm, theo dõi và dự báo chuyển động hạn ngắn của các ổ mây dông. Trái ngược với TITAN, việc sử dụng đa ngưỡng PHVT $(30,35,40,45,50,55,60 \mathrm{dBZ})$ trong thuật toán của SCIT đã cải thiện đáng kể hiệu suất nhận dạng các ổ mây dông. Mặc dù SCIT đủ mạnh để xác định các ổ dông trong một cụm dông nhưng không thể phát hiện sự khởi đầu hoặc các cơn dông có PHVT nhỏ hơn $30 \mathrm{dBZ}$. Nhằm mục đích cải thiện hiệu quả của TITAN, năm 2009, thuật toán TITAN đã được cải tiến với tên gọi ETITAN sử dụng đa ngưỡng để phát hiện bão đối lưu [4]. ETITAN cải tiến thuật toán TITAN ban đầu ở ba khía cạnh. Đầu tiên, để xử lý vấn đề hợp nhất sai khi hai ổ dông ở gần nhau và để cô lập các ổ dông riêng lẻ, ETITAN sử dụng phương pháp nhận dạng đa ngưỡng. Thứ hai, trong giai đoạn theo dõi, ETITAN đề xuất phương pháp tối ưu hóa tổ hợp dựa trên ràng buộc động để theo dõi các cơn dông. Cuối cùng, ETITAN sử dụng trường vectơ chuyển động được tính bằng phương pháp tương quan chéo để dự báo vị trí của các ổ dông biệt lập riêng lẻ. ETITAN đã kết hợp được cả hai phương pháp tương quan chéo và phương pháp kiểu trung tâm để cải thiện hiệu suất dự báo.

Trong hội thảo về dự báo tức thời ổ dông đối lưu, [2] cho biết TITAN đã được ứng dụng rộng rãi trong nhiều hệ thống dự báo trên khắp thế giới, ví dụ như: Hoa Kì, Mexico, Đài Loan, Brazil, Úc, Nam Phi,... Gần đây, phần mềm TITAN cũng được ứng dụng trong công nghệ dự báo thời tiết hạn ngắn và cực ngắn các vùng đối lưu hoạt động mạnh phục vụ cho dịch vụ khí tượng hàng không tại Trung Quốc [8]. Kết quả nghiên cứu này cho thấy đã cải thiện phần nào độ chính xác dự báo hạn ngắn và dự báo tức thời các hiện tượng thời tiết đối lưu khắc nghiệt.

Tại Việt Nam, [11] đã nghiên cứu ứng dụng phần mềm TITAN để nhận dạng, theo dõi, phân tích tức thời dông cho khu vực thành phố Hồ Chí Minh. Tác giả sử dụng thuật toán Tstorms2Symprod trong phần mềm TITAN để xác định ổ dông và sự di chuyển ổ dông trong 1 giờ tới thông qua PHVT của ra đa Nhà Bè thời gian thực. Nghiên cứu cho thấy phần mềm TITAN có thể nẳm bắt được vị trí, hướng và vận tốc di chuyển, quy mô của các ổ dông trong khu vực nghiên cứu.

Tuy nhiên, cho đến nay phương pháp TITAN của Dixon và Wiener vẫn là một phương pháp phổ biến nhưng phần mềm liên quan khó thiết lập và sử dụng. Thuật toán được phát triển mới để theo dõi các ổ mây dông được xây dựng trên ngôn ngữ Python dựa trên phần mềm TITAN. So với TITAN, thuật toán mới này được thiết kế đơn giản hơn. Mục đích của nghiên cứu là phát triển một thuật toán mới để theo dõi quỹ đạo di chuyển của các ổ mây dông dựa trên nguyên lý của phần mềm TITAN và cải thiện cho phù hợp với điều kiện Việt Nam. Do vậy, nghiên cứu này sẽ giới thiệu phương pháp xây dựng công cụ theo dõi quỹ đạo di chuyển của vùng mây dông và các thử nghiệm theo dõi các ổ mây dông trong một số trường hợp mưa dông xảy ra tại Việt Nam vào tháng 9 năm 2020. Mô tả chi tiết về phương pháp và các kết quả thử nghiệm sẽ được trình bày tương ứng tại mục 2 và mục 3 trong nghiên cứu này.

\section{Phương pháp nghiên cứu}

Phương pháp theo dõi các ổ mây dông làm việc trực tiếp với đối tượng lưới Py-ART dựa trên phần mềm TITAN. Phương pháp này không giải quyết sự phân tách hoặc hợp nhất nhưng an toàn trong việc theo dõi chuỗi và khi dữ liệu ra đa bị phân kỳ do các sự kiện dông. Phương pháp mới trong nghiên cứu này sử dụng thuật toán $\mathrm{N}$ bước để liên kết các ổ dông qua các bước thời gian $\mathrm{t}_{0}$ và $\mathrm{t}_{1}$ :

- Việc xác định các ổ dông dựa trên các ngưỡng tối thiểu của diện tích ổ dông và giá trị trường PHVT. 
- Tương quan pha được thực hiện trong một vùng lân cận xung quanh mỗi ổ dông để đưa ra một vectơ ước tính dịch chuyển. Các ước tính vectơ dịch chuyển được hiệu chỉnh dựa trên chuyển động của ổ dông trước đó.

- Đối với mỗi ổ dông được xác định tại thời điểm to, thuật toán sẽ tìm kiếm các ổ dông tại thời điểm $\mathrm{t}_{1}$. cùng.

- Sử dụng thuật toán Hungary để so sánh các ổ tiềm năng và tìm ra cặp ổ tối ưu cuối

- Vị trí ổ dông được cập nhật và thống kê lại. Các ổ dông mới sẽ được chỉ định chỉ số nhận dạng mới.

Chương trình bao gồm 10 mô đun tính toán với các đặc điểm được mô tả trong Bảng 1.

Bảng 1. Các mô đun tính toán trong chương trình.

\begin{tabular}{|c|c|c|}
\hline STT & Tên mô đun & Đặc điểm \\
\hline 1 & data.utils.py & Thu thập và xử lý dữ liệu ra đa. \\
\hline 2 & grid_utils.py & $\begin{array}{l}\text { Xử lý dữ liệu ra đa và chuyển sang dạng lưới của ứng dụng pyart, lọc bỏ các vùng } \\
\text { có phản hồi vô tuyến nhỏ, tính toán kích thước } 3 \text { chiều của lưới. }\end{array}$ \\
\hline 3 & helpers.py & Đếm và ghi lại lịch sử di chuyển của các ổ dông. \\
\hline 4 & matching.py & $\begin{array}{l}\text { Xử lý tối đa } 1000 \text { cặp dông, tính toán khoảng cách gữa hai véc tơ, tính toán sự } \\
\text { thay đổi kích thước vùng phản hồi vô tuyến, tìm kiếm đối tượng, xử lý độ lệch } \\
\text { không nhất quán, hiệu chỉnh độ lệch, dự báo và tìm kiếm mở rộng ổ dông ở thời } \\
\text { điểm sau,... }\end{array}$ \\
\hline 5 & objects.py & $\begin{array}{l}\text { Hàm để quản lý và ghi lại các đặc tính của đối tượng, bao gồm xác định tâm của } \\
\text { đối tượng để gắn ID, xác định các tham số về bán kính, diện tích và tâm của đối } \\
\text { tượng, lọc bỏ các đối tượng bị tan rã, cập nhật các đối tượng đang tồn tại và tạo ID } \\
\text { mới cho các đối tượng mới sinh ra, gắn các thông tin đầu cuối vào từ điển cho đối } \\
\text { tượng hiện tại, kiểm tra các đối tượng dông đơn lẻ theo một ngướng xác định } \\
\text { trước, tính toán giá trị phản hồi lớn nhất của đối tượng dông đúng, tính toán đặc } \\
\text { tính của đối tượng cho tất cả các đối tượng tìm thấy, viết ra quỹ đạo của ổ dông,... }\end{array}$ \\
\hline 6 & $\begin{array}{l}\text { phase_correlation } \\
\text {.py }\end{array}$ & $\begin{array}{l}\text { Là hàm để tính tương quan pha, sử dụng để dự báo sự chuyển động giữa các lần } \\
\text { quét. }\end{array}$ \\
\hline \multirow[b]{2}{*}{7} & \multirow[b]{2}{*}{ tracks.py } & $\begin{array}{l}\text { Là class chính, cho phép theo dõi quỹ đạo ổ dông, bao gồm các tham số: } \\
\text { - FIELD_THRESH: được sử dụng để phát hiện đối tượng. Các đối tượng được } \\
\text { phát hiện là các pixel được kết nối trên ngưỡng này } \\
\text { - ISO_THRESH: được sử dụng trong phân loại ô dông đơn lẻ. } \\
\text { - ISO_SMOOTH: tham số làm mịn Gaussian trong tiền xử lý phát hiện cường độ } \\
\text { phản hồi vô tuyến đạt đỉnh } \\
\text { - MIN_SIZE: Ngưỡng kích thước tối thiểu tính bằng pixel để phát hiện đối tượng } \\
\text { - SEARCH_MARGIN: Bán kính của hộp tìm kiếm xung quanh tâm đối tượng } \\
\text { được dự đoán }\end{array}$ \\
\hline & & $\begin{array}{l}\text { - FLOW_MARGIN: kích thước vùng xung quanh phạm vi đối tượng để thực } \\
\text { hiện tương quan về pha. } \\
\text { - MAX_DISPARITY: Giá trị chênh lệch tối đa cho phép } \\
\text { - MAX_FLOW_MAG: Độ lớn dịch chuyển toàn cầu tối đa cho phép } \\
\text { - MAX_SHIFT_DISP: độ lớn tối đa của sự khác biệt tính bằng } \mathrm{m} / \mathrm{s} \text { cho hai độ } \\
\text { lệch được cho là thỏa mãn } \\
\text { - GS_ALT: độ cao tính bằng } \mathrm{m} \text { để thực hiện tương quan về pha cho tính toán dịch } \\
\text { chuyền toàn cầu (chỉ sử dụng chỉ sồ này trong trường hợp dữ liệu ra đa là cường } \\
\text { độ PHVT) }\end{array}$ \\
\hline 8 & visualization.py & Là công cụ để minh họa quỹ đạo di chuyển của các đối tượng \\
\hline 9 & setup.py & Để cài đặt các gói phần mềm cần thiết \\
\hline 10 & init_.py & Thông tin các mô đun của chương trình \\
\hline
\end{tabular}


Để sử dụng được gói chương trình này cần cài đặt các thư viện cần thiết như NumPy, Pandas, SciPy, Matplotlib, Cartopy, Py-ART, ffmpeg. Do vậy chương trình có cấu trúc đơn giản, dễ dàng thiết lập và cài đặt để sử dụng, dữ liệu lịch sử di chuyển của cơn dông cũng được lưu trữ để phục vụ việc phân tích thống kê. Chương trình được viết để xử lý tất cả các loại dữ liệu ra đa của Việt Nam, có thể sử dụng để theo dôi quỹ đạo di chuyển cho từng loại ra đa riêng lẻ hoặc cho tổ hợp các ra đa của Việt Nam.

Chương trình theo dõi ổ mây dông nàysẽ cho biết quá trình khoanh vùng, nhận diện và theo dõi các đám mây dông. Đối với các đám mây dông phát triển thì sẽ xuất hiện đường quỹ đạo di chuyển của đám này. Mỗi đám dông được ký hiệu bằng một số hiệu ID duy nhất. Với đám mây dông chỉ xuất hiện và suy yếu ngay và không có sự liên kết với các ô pixel lân cận thì sẽ được tách ra với ID mới.

Hình 1 là sơ đồ mô tả thuật toán theo dõi quỹ đạo ổ dông được sử dụng trong nghiên cứu này:

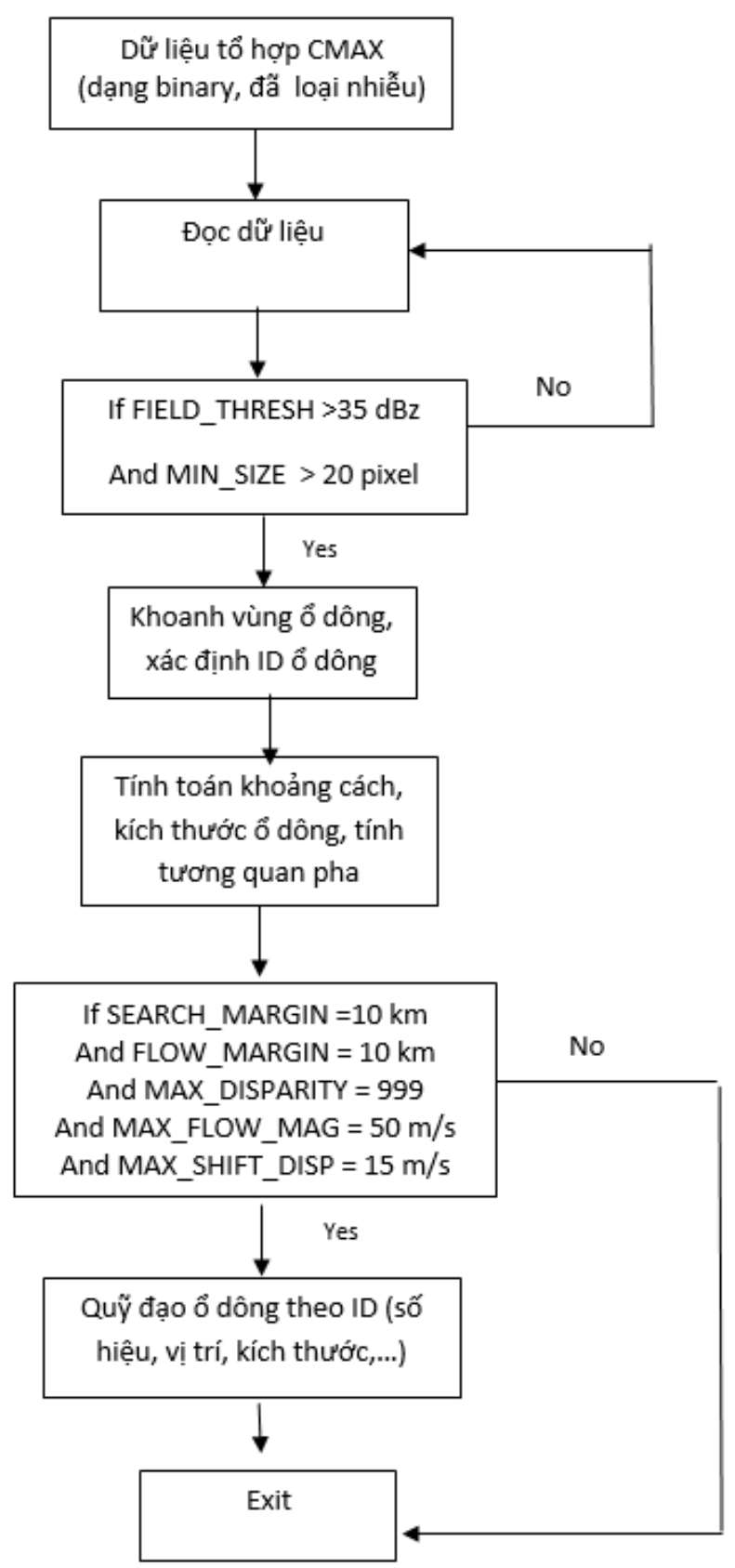

Hình 1. Sơ đồ mô tả thuật toán theo dõi quỹ đạo ổ dông. 
Nghiên cứu này đã tiến hành thử nghiệm chương trình theo dõi ổ dông cho trường hợp mưa dông gây ảnh hưởng chủ yếu tới khu vực tây bắc do ra đa Pha Đin quan trắc được vào ngày 23/9/2020 và trường hợp mưa dông tại khu vực tỉnh Kon Tum và Đăk Nông ngày 27/2/2021 do ra đa Pleiku quan trắc được. Ngưỡng được thiết lập cho các thử nghiệm trên là ngưỡng phát hiện dông $35 \mathrm{dBZ}$ và có diện tích từ 20 pixel trở lên.

\section{Kết quả thử nghiệm}

\subsection{Thử nghiệm theo dõi quỹ đạo dông với trường hợp ra đa Pha Đin quan trắc được ngày} 23/9/2020

Trong khoảng thời gian từ ngày 23/9-24/9/2020, do ảnh hưởng của không khí lạnh nén rãnh áp thấp kết hợp với hội tụ gió trên mực 1500 m nên ở Bắc Bộ có mưa vừa, mưa to, có nơi mưa rất to và rải rác có dông với lượng mưa phổ biến $50-100 \mathrm{~mm} / 24 \mathrm{~h}$; các tỉnh Lai Châu, Điện Biên, Lào Cai, Yên Bái, Hà Giang, Tuyên Quang, Thái Nguyên, Bắc Cạn có nơi trên $150 \mathrm{~mm} / 24 \mathrm{~h}$. Hình 1 mô tả sự dịch chuyển của các đám mây dông dựa vào thuật toán phát triển ở mục 2 cho trường hợp dông ngày 23/9/2020.

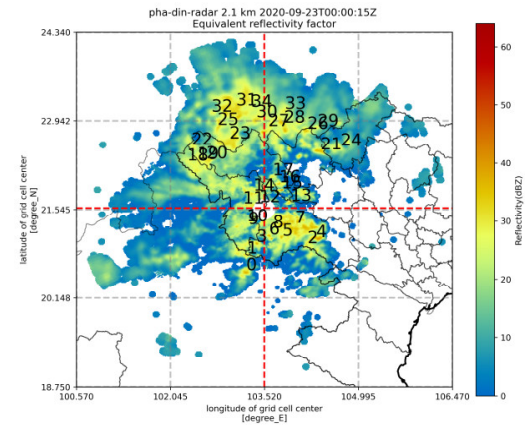

a. $00 \mathrm{~h} 00 \mathrm{UTC}$

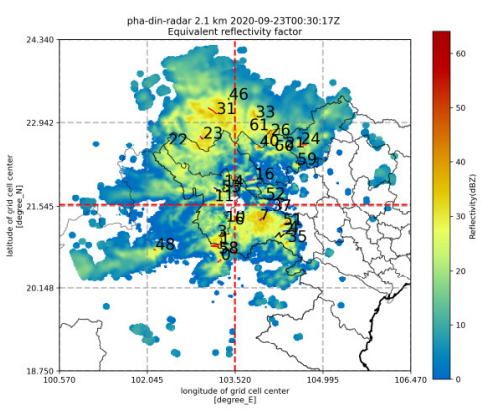

d. $00 \mathrm{~h} 30 \mathrm{UTC}$

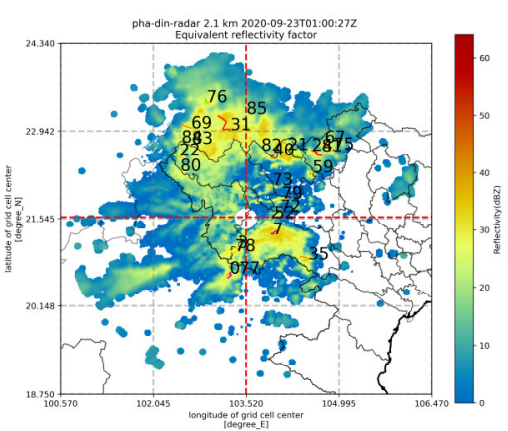

g. $01 \mathrm{~h} 00 \mathrm{UTC}$

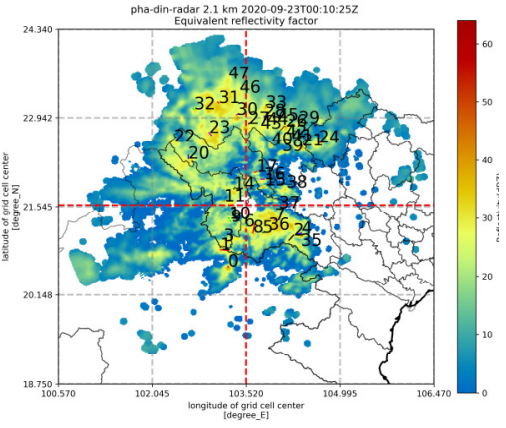

b. 00h10 UTC

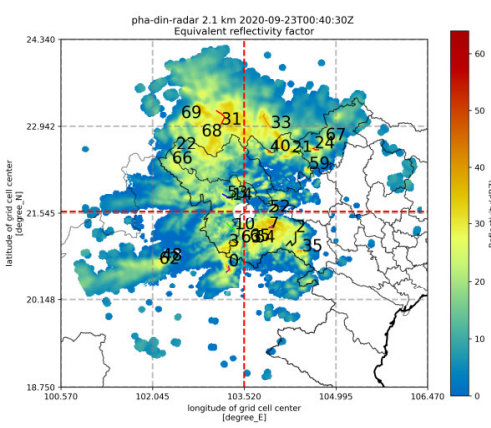

e. $00 \mathrm{~h} 40 \mathrm{UTC}$

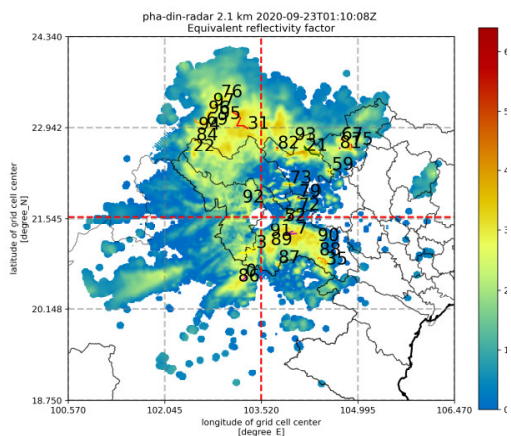

h. $01 \mathrm{~h} 10 \mathrm{UTC}$

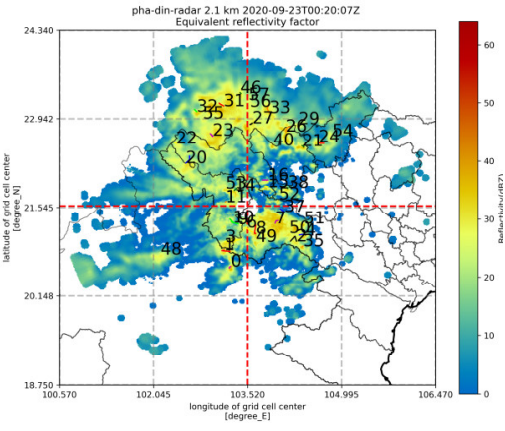

c. 00h20 UTC

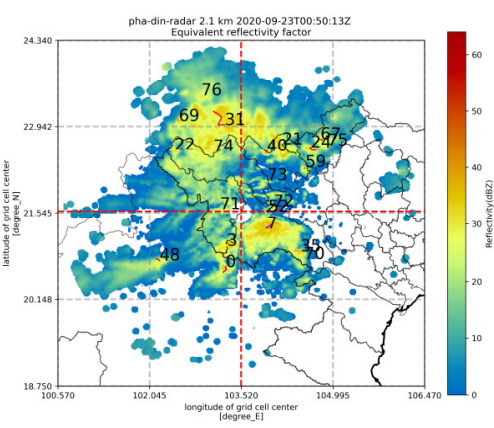

f. $\quad 00 \mathrm{~h} 50 \mathrm{UTC}$

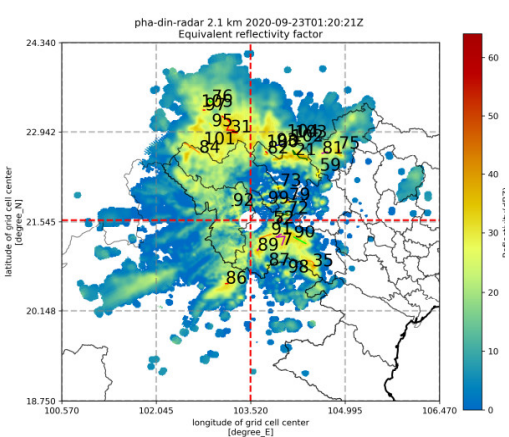

i. $\quad 01 \mathrm{~h} 20 \mathrm{UTC}$ 


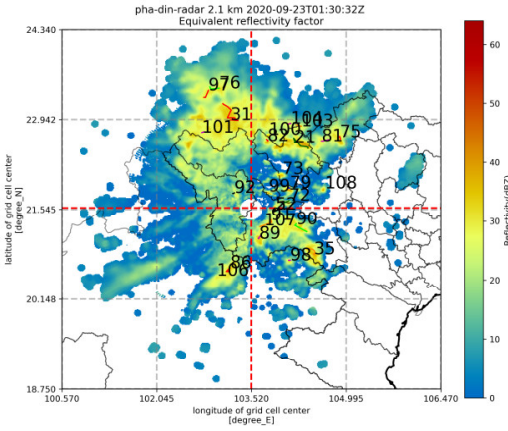

j. $\quad 01 \mathrm{~h} 30$ UTC

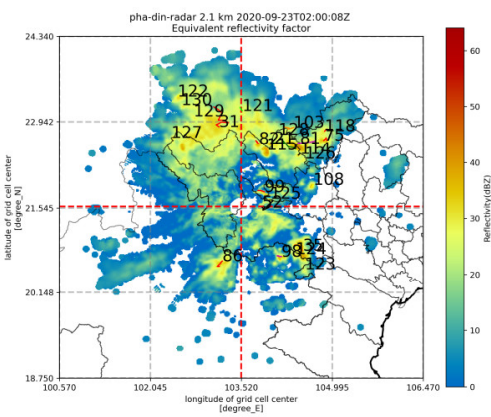

m. $02 \mathrm{~h} 00 \mathrm{UTC}$

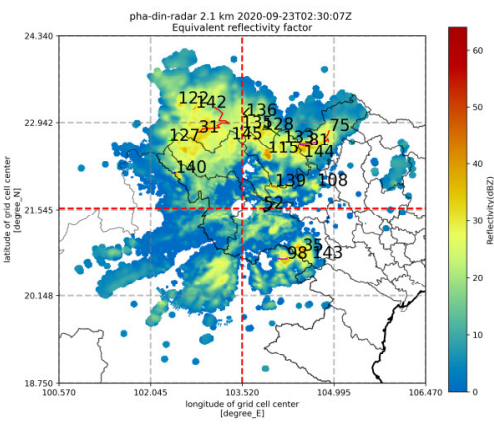

p. $02 \mathrm{~h} 30 \mathrm{UTC}$

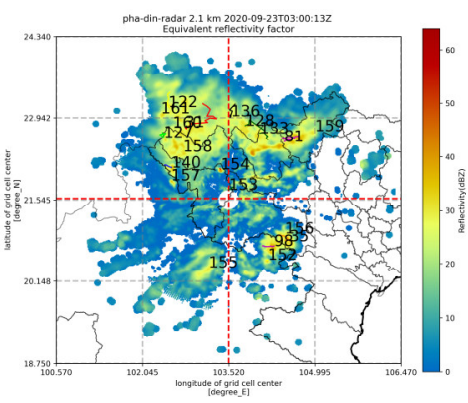

s. 03 h00 UTC

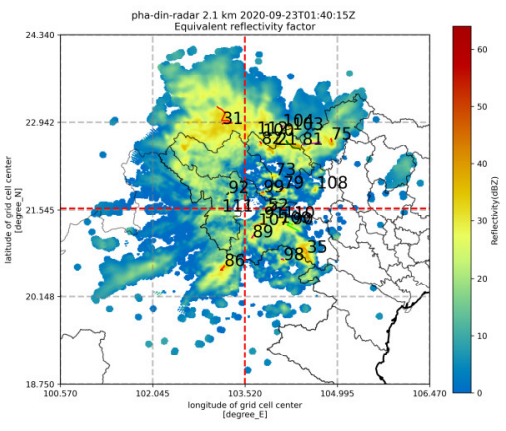

k. $01 \mathrm{~h} 40$ UTC

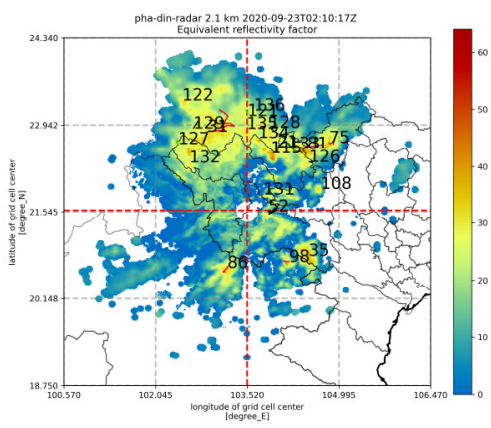

n. $02 \mathrm{~h} 10 \mathrm{UTC}$

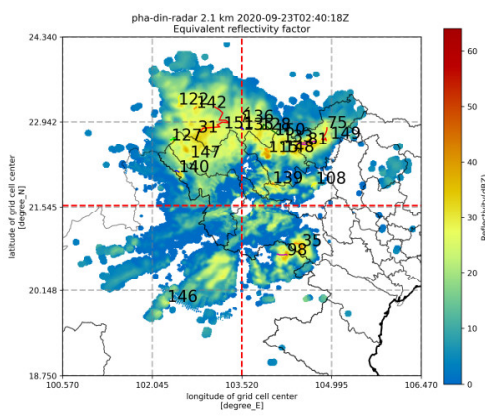

q. $02 \mathrm{~h} 40 \mathrm{UTC}$

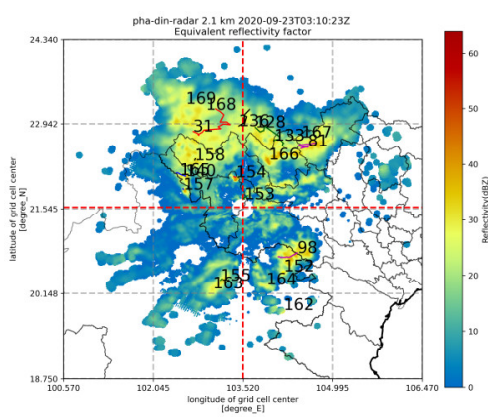

t. $03 \mathrm{~h} 10 \mathrm{UTC}$

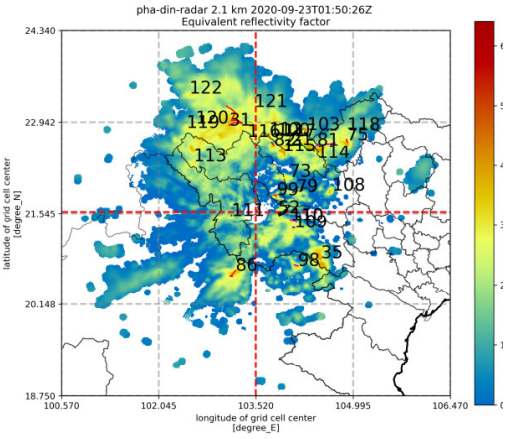

1. $01 \mathrm{~h} 50 \mathrm{UTC}$

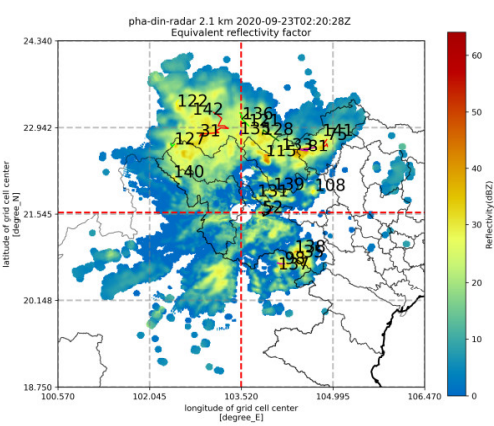

o. $02 \mathrm{~h} 20 \mathrm{UTC}$

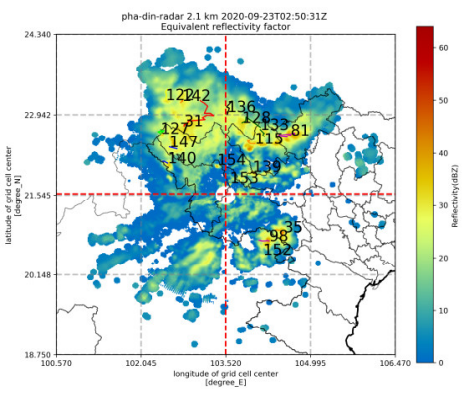

r. $02 \mathrm{~h} 50 \mathrm{UTC}$

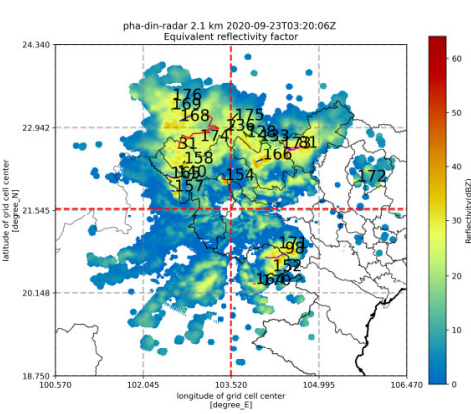

u. $03 h 20$ UTC 


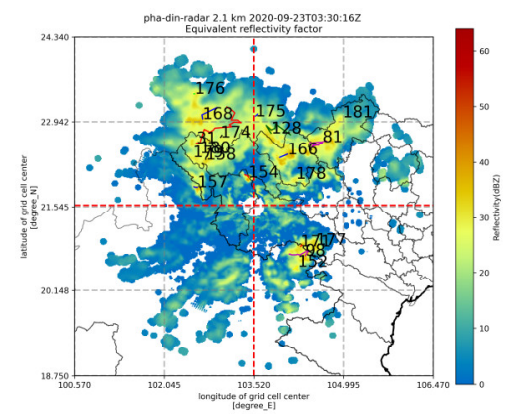

v. $03 h 30$ UTC

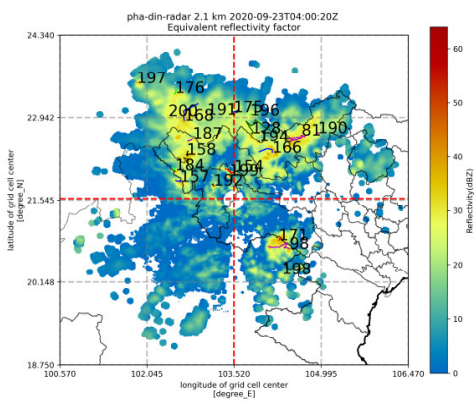

y. $04 \mathrm{~h} 00$ UTC

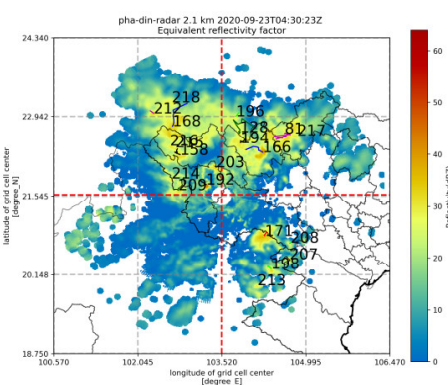

bb. $04 h 30$ UTC

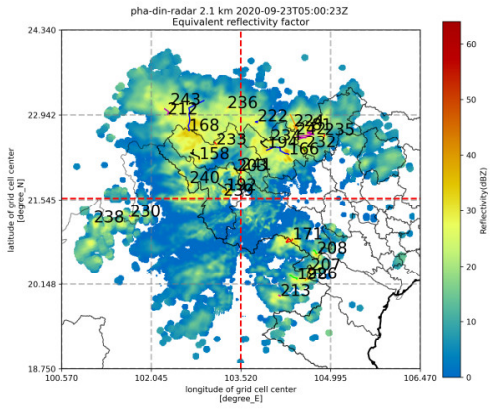

ee. $05 \mathrm{~h} 00 \mathrm{UTC}$

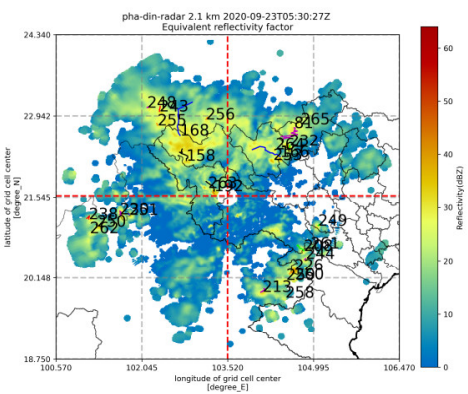

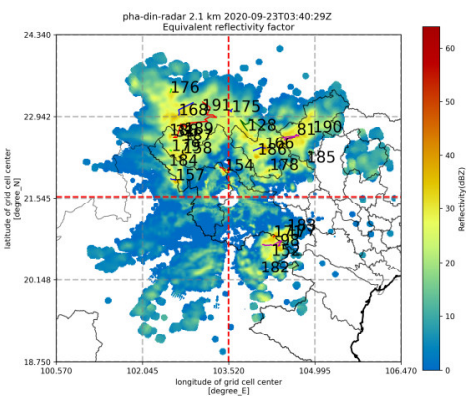

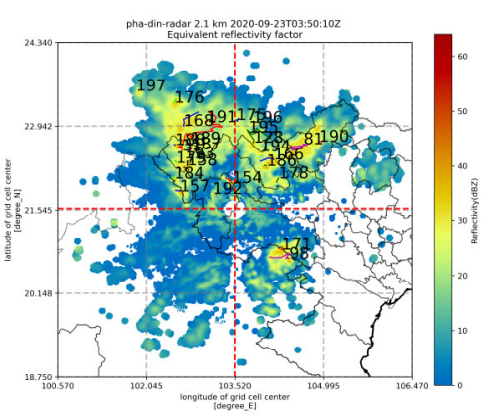

w. $03 \mathrm{~h} 40 \mathrm{UTC}$

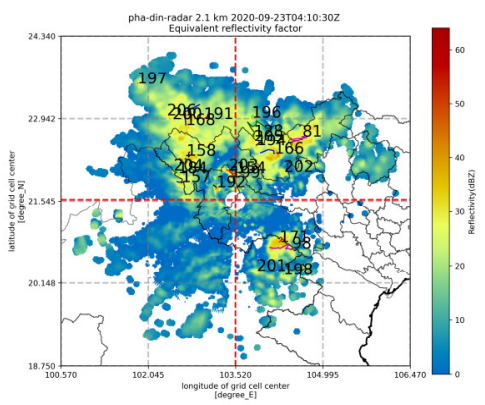

z. $04 \mathrm{~h} 10$ UTC

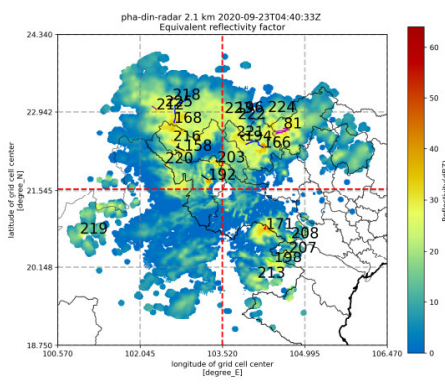

cc. $04 \mathrm{~h} 40 \mathrm{UTC}$

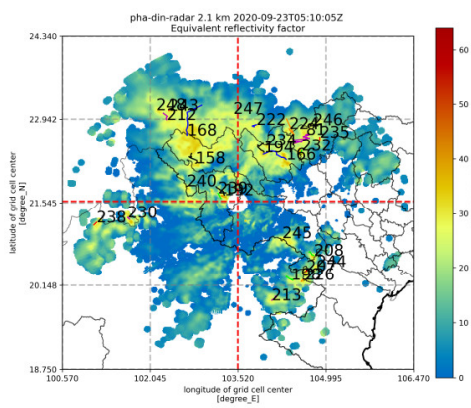

ff. $05 \mathrm{~h} 10 \mathrm{UTC}$

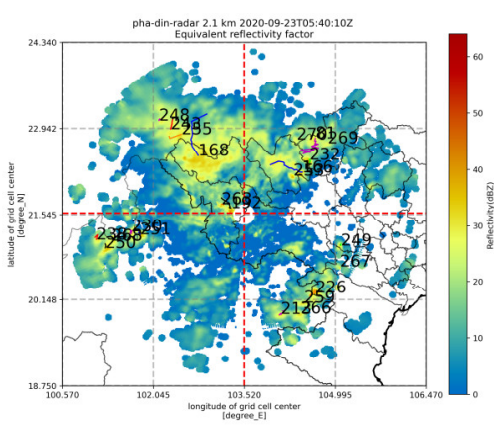

x. 03h50 UTC

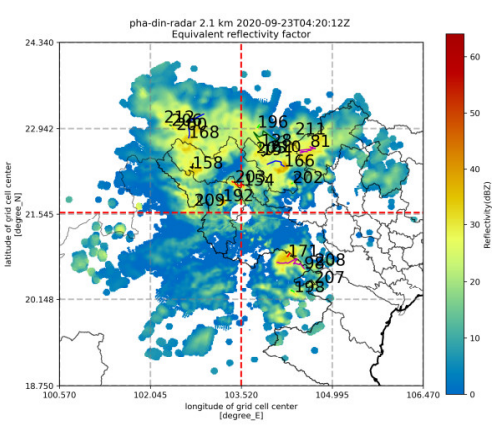

aa. $04 \mathrm{~h} 20 \mathrm{UTC}$

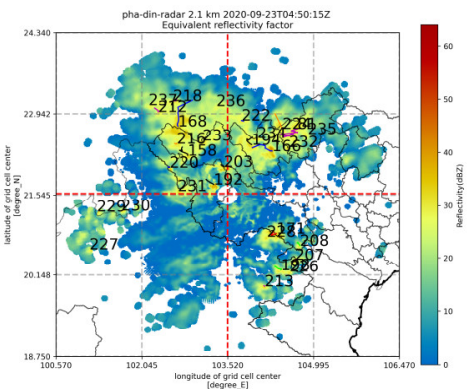

dd. 04h50 UTC

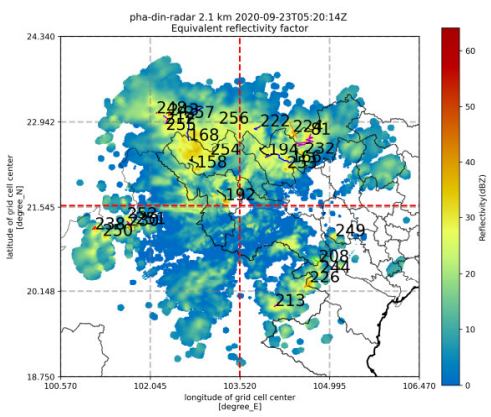

gg. $05 \mathrm{~h} 20 \mathrm{UTC}$

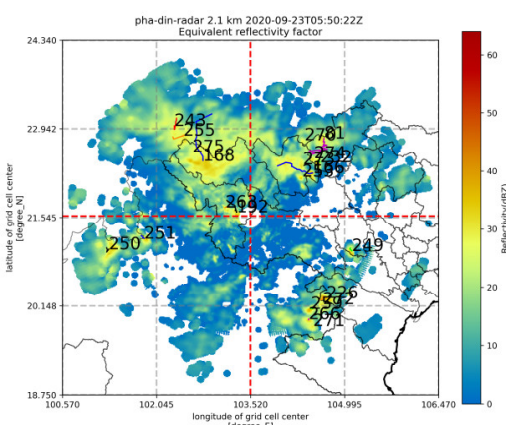


hh. 05 h30 UTC

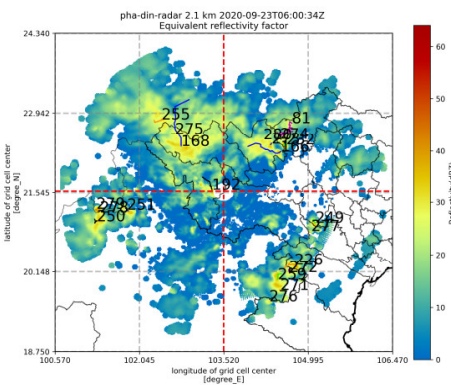

kk. 06h00 UTC

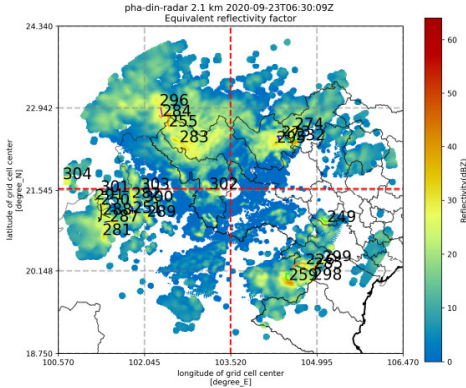

nn. $06 h 30$ UTC

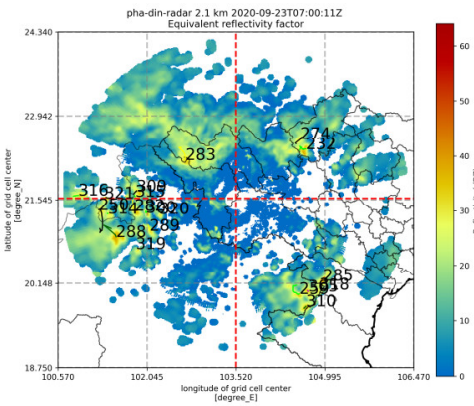

qq. 07h00 UTC

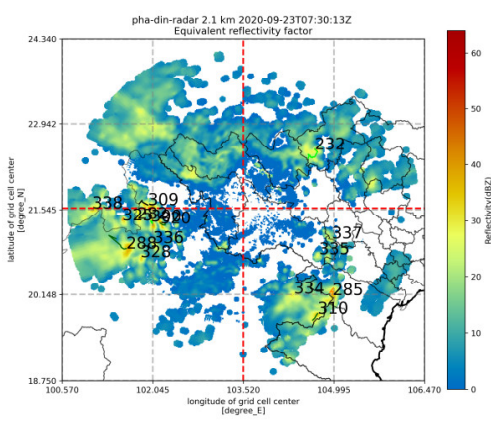

tt. $07 \mathrm{~h} 30 \mathrm{UTC}$

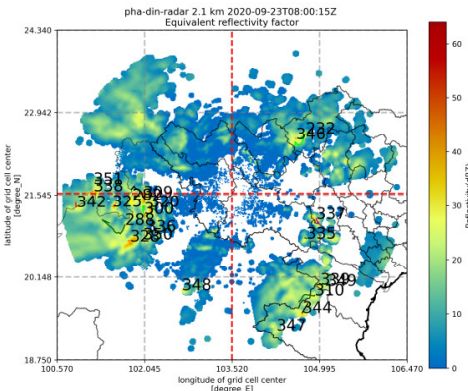

ww. 08h00 UTC ii. $05 \mathrm{~h} 40 \mathrm{UTC}$

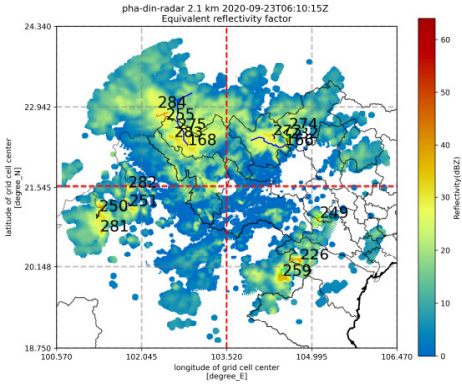

11. $06 \mathrm{~h} 10 \mathrm{UTC}$

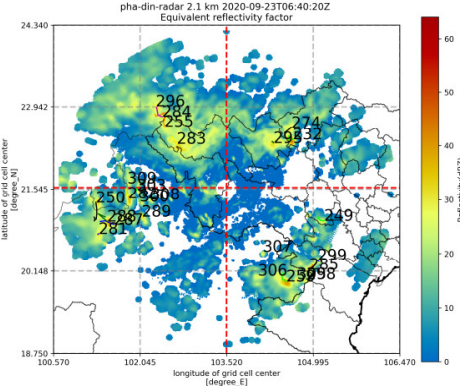

oo. $06 \mathrm{~h} 40 \mathrm{UTC}$

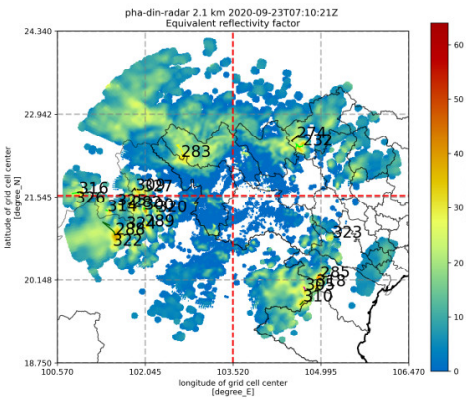

rr. $07 \mathrm{~h} 10 \mathrm{UTC}$

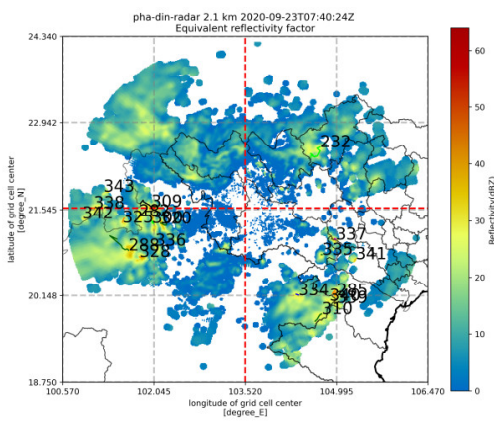

uu. $07 \mathrm{~h} 40 \mathrm{UTC}$

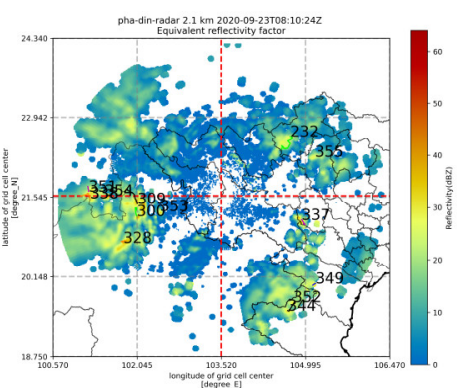

xx. 08h10 UTC jj. $\quad 05 \mathrm{~h} 50$ UTC

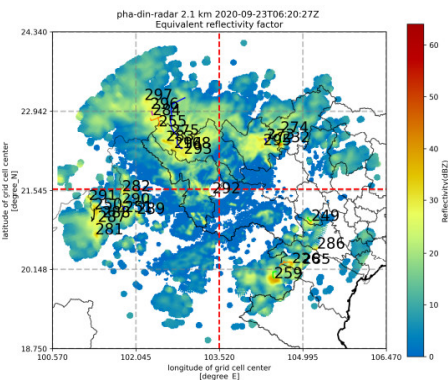

mm. 06h20 UTC

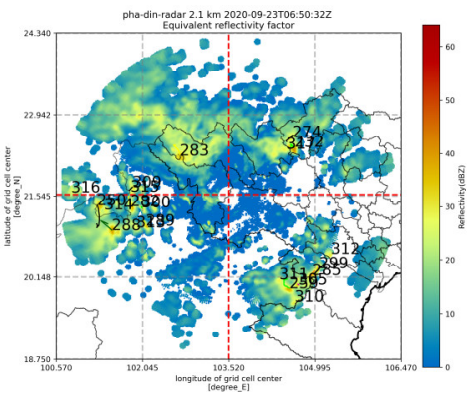

pp. 06h50 UTC

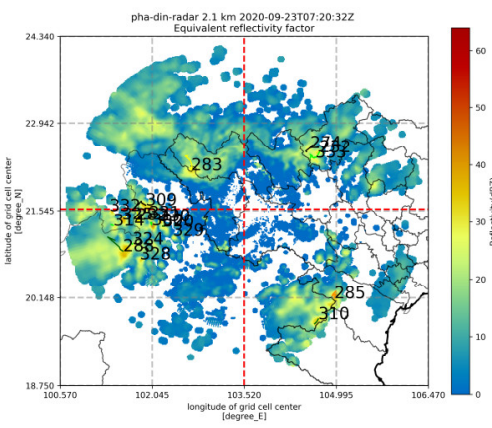

ss. $07 h 20$ UTC

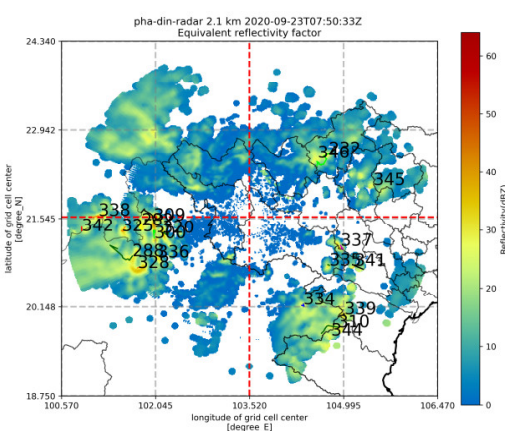

vv. 07h50 UTC

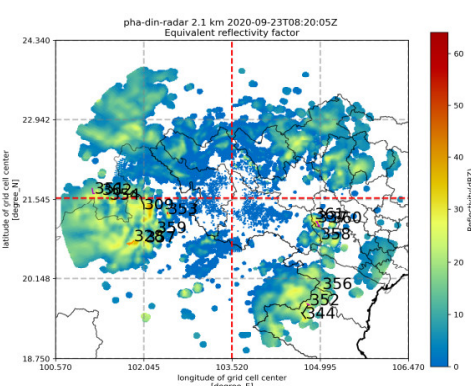

yy. 08h20 UTC 


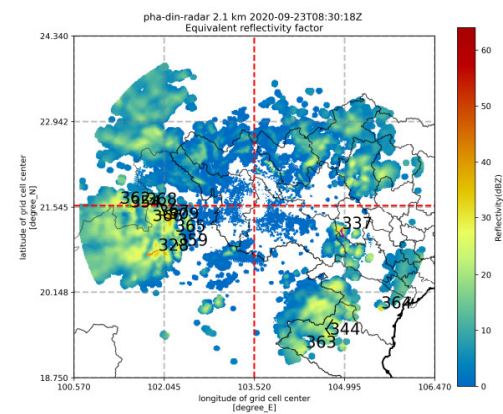

zz. $08 \mathrm{~h} 30 \mathrm{UTC}$

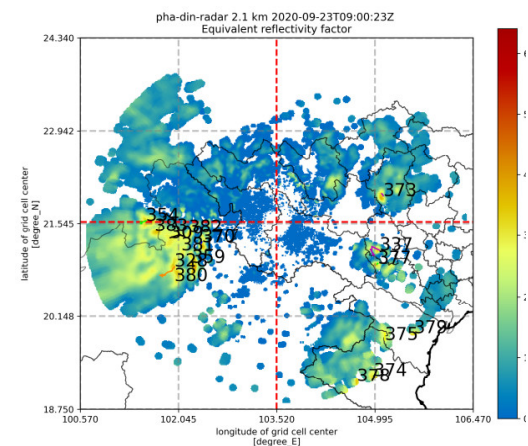

ccc. 09h00 UTC

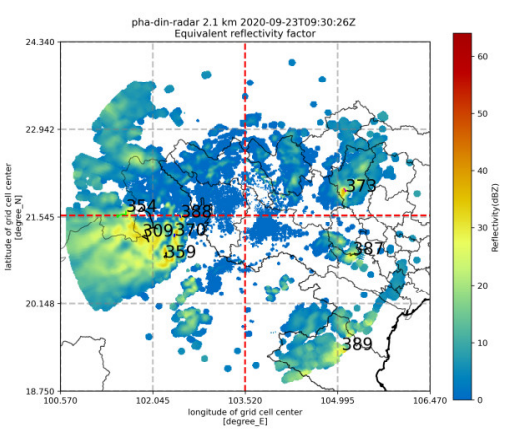

fff. 09 h30 UTC

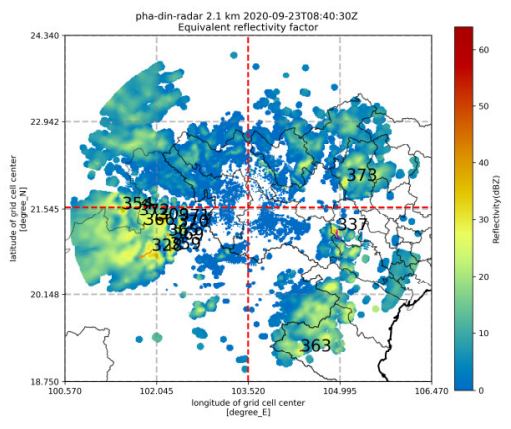

aaa. $08 \mathrm{~h} 40 \mathrm{UTC}$

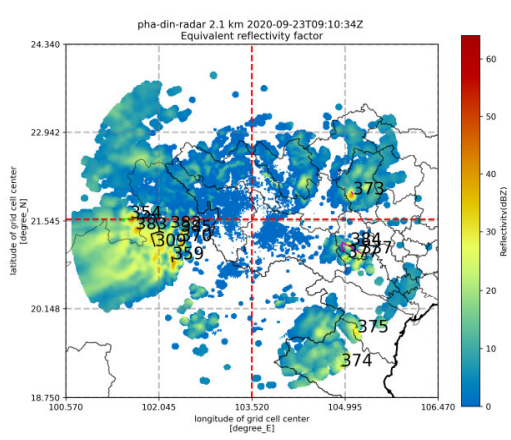

ddd. 09h10 UTC

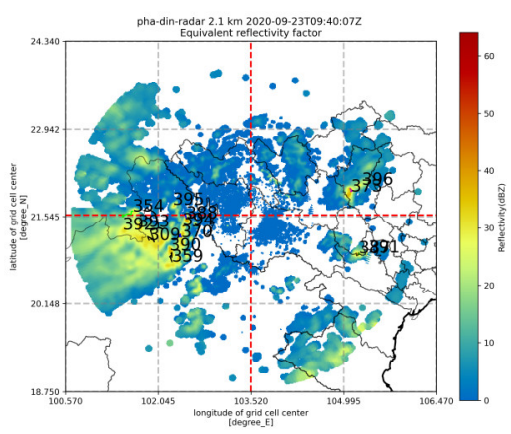

ggg. 09h40 UTC

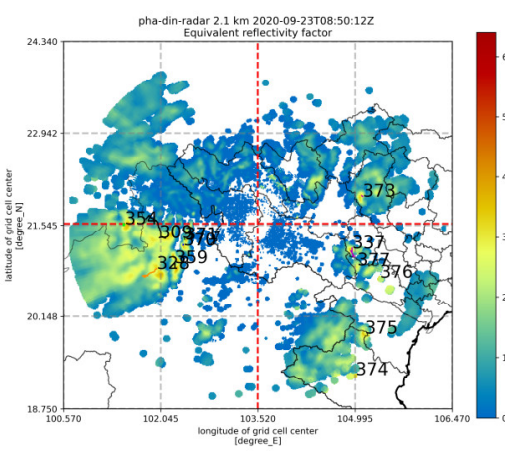

bbb. 08 h50 UTC

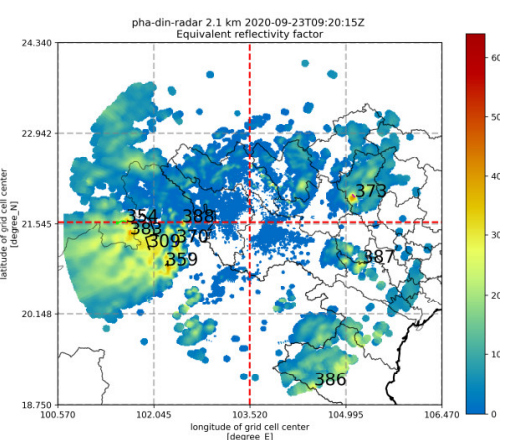

eee. $09 \mathrm{~h} 20 \mathrm{UTC}$

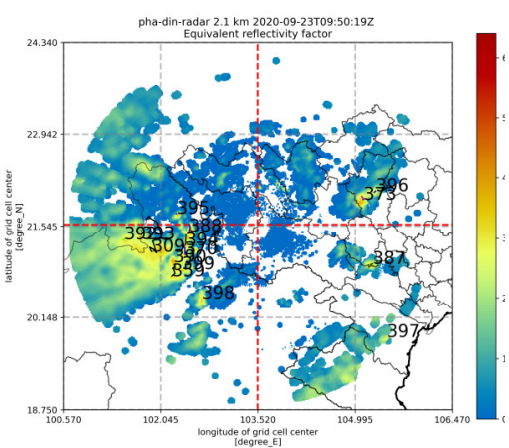

hhh. 09h50 UTC

Hình 2. Theo dõi quỹ đạo dông từ 00h00 (UTC) đến 09h50 (UTC) ngày 23/9/2020.

Hình 2 cho thấy số lượng cơn dông mà thuật toán xác định được là 398 cơn dông. Trong đó hầu hết là các cơn dông đơn lẻ tồn tại trong thời gian ngắn, xuất hiện và suy yếu nhanh; một vài cơn dông có số hiệu $0,31,35,81$ và 98 có thời gian tồn tại lâu nhất. Cơn dông có số hiệu 0 tồn tại từ $00 \mathrm{~h} 00$ UTC đến $01 \mathrm{~h} 10 \mathrm{UTC}$, cơn dông số hiệu 31 tồn tại từ $00 \mathrm{~h} 00 \mathrm{UTC}$ đến 03h50UTC, cơn dông số hiệu 35 tồn tại từ 00h00 UTC đến 03h20 UTC, cơn dông có số hiệu 81 tồn tại từ 01 h00 UTC đển $06 h 00$ UTC, ... Quỹ đạo các cơn dông này không có quy luật nhất định nào cả. Trong trường hợp này, các ổ dông nằm trong hệ thống mây dông có quy mô rộng lớn, sự dịch chuyển và thay đổi cường độ phụ thuộc nhiều vào hình thế thời tiết quy mô lớn chi phối. Chương trình theo dõi quỹ đạo ổ mây dông trong thử nghiệm này đã bắt được quỹ đạo di chuyển vùng mây dông, nhưng tính hệ thống khó có thể tổng quát hoá được với điều kiện đặt ra là vùng mây dông có độ phản hồi vô tuyến trên $35 \mathrm{dBZ}$ và có diện tích là từ 20 pixel trở lên.

\subsection{Thử nghiệm theo dõi quỹ đạo dông xảy ra mua dông cuc bộ tại tỉnh Kon Tum và Đăk Nông ngày 27/2/2021}

Đây là trường hợp thử nghiệm theo dõi quỹ đạo dông cho cơn dông đơn ổ được phát hiện bởi hệ thống ra đa Pleiku có thời gian tồn tại ngắn, cơn dông này đã gây ra mưa rào và dông 
cho khu vực tỉnh Kon Tum và Đăk Nông. Để mô phỏng được sự di chuyển của các đám mây dông do cơn dông này gây ra, dữ liệu ra đa Pleiku từ $10 \mathrm{~h} 50$ (UTC) đến $13 \mathrm{~h} 20$ ngày 27/2/2021 đã được thu thập để đưa vào tính toán.

Hình 3 mô tả sự dịch chuyển của các ổ mây dông từ thời điểm $10 \mathrm{~h} 50$ (UTC) đến $13 \mathrm{~h} 20$ (UTC) ngày 27/2/2021 với khoảng thời gian là 10 phút một.

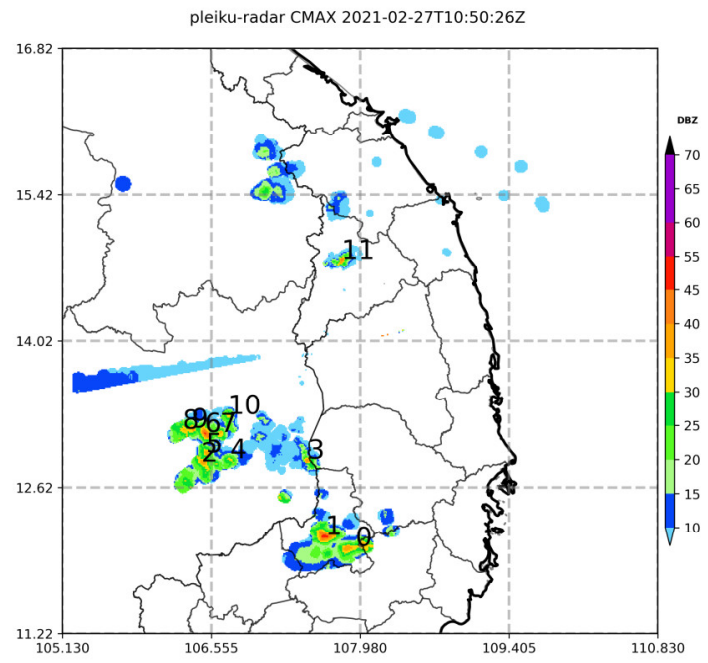

a. $10 \mathrm{~h} 50 \mathrm{UTC}$

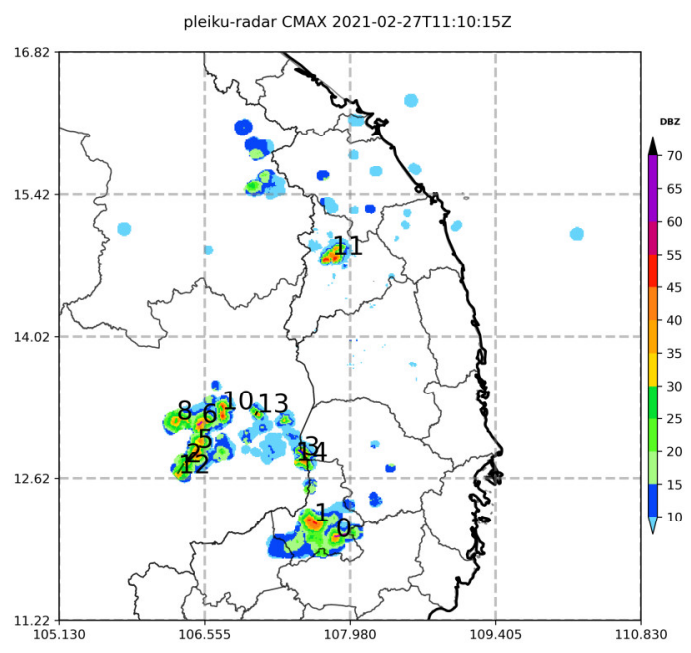

c. $11 \mathrm{~h} 10 \mathrm{UTC}$

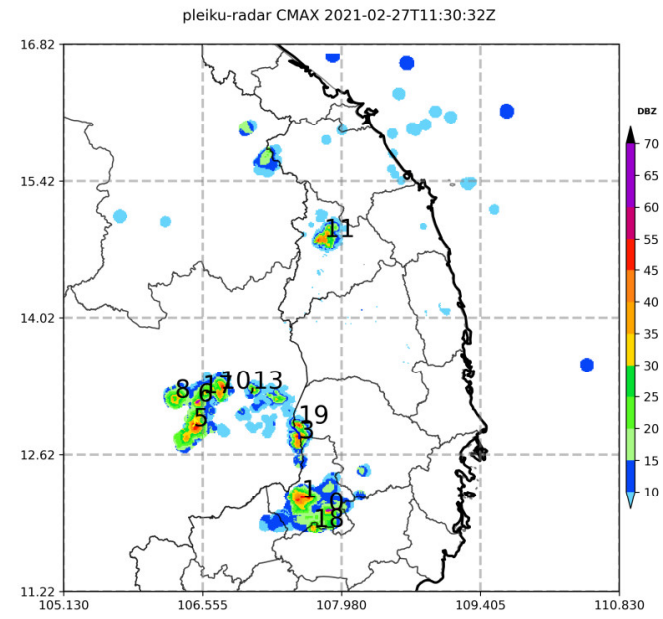

e. $11 \mathrm{~h} 30 \mathrm{UTC}$

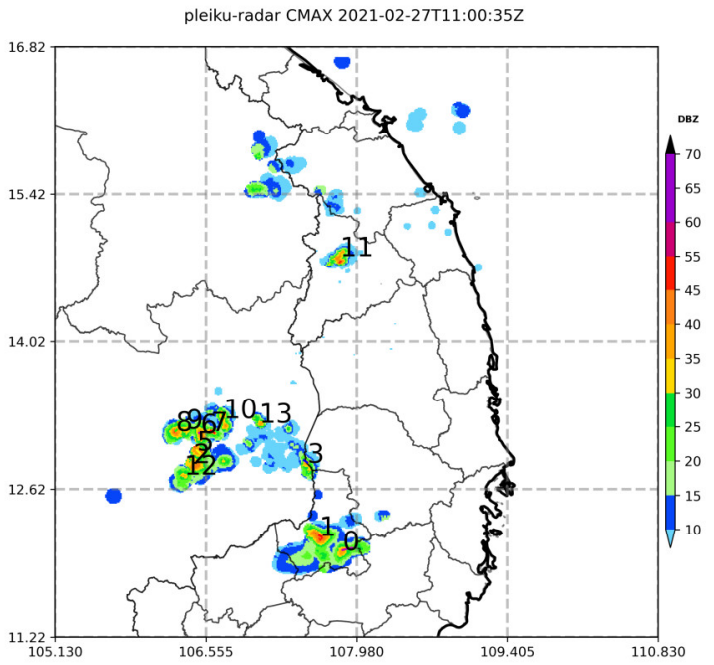

b. $\quad 11 \mathrm{~h} 00 \mathrm{UTC}$

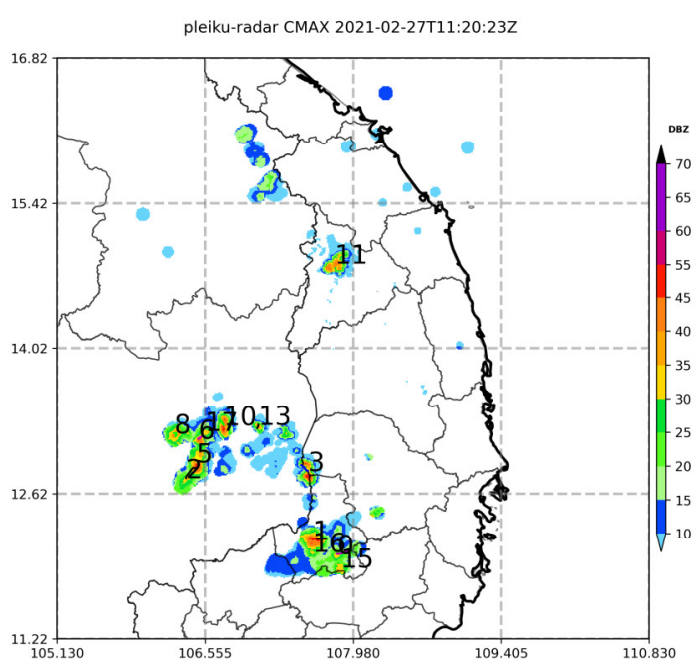

d. $11 \mathrm{~h} 20 \mathrm{UTC}$

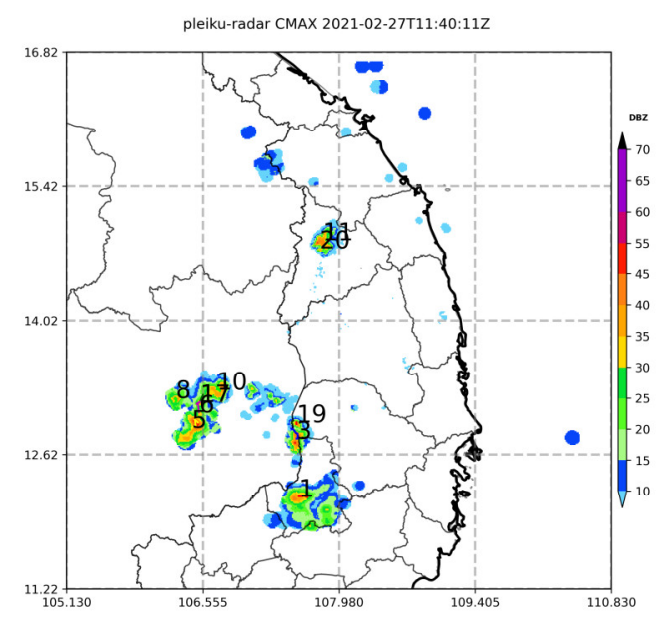

f. $\quad 11 \mathrm{~h} 40 \mathrm{UTC}$ 


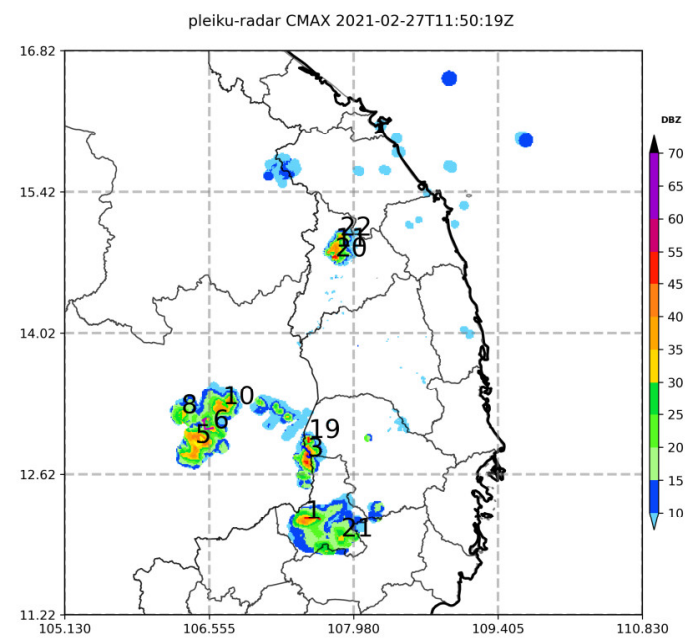

g. $11 \mathrm{~h} 50 \mathrm{UTC}$

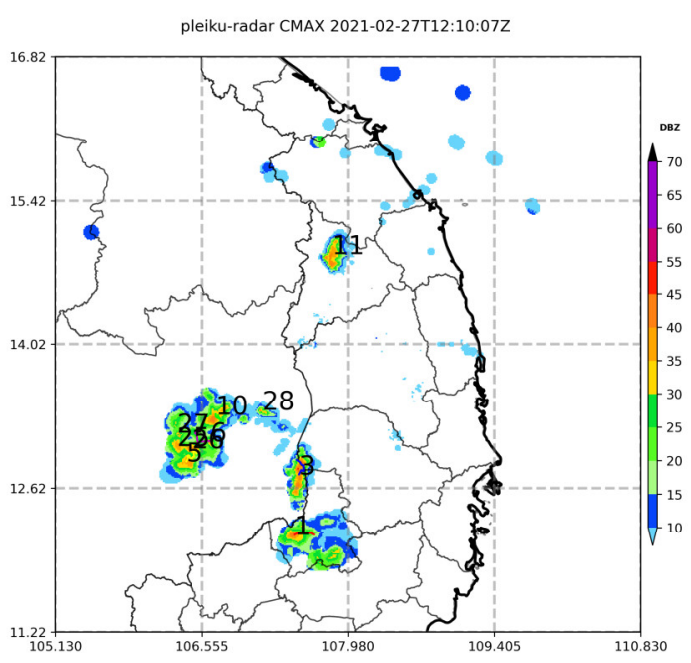

i. $12 \mathrm{~h} 10 \mathrm{UTC}$

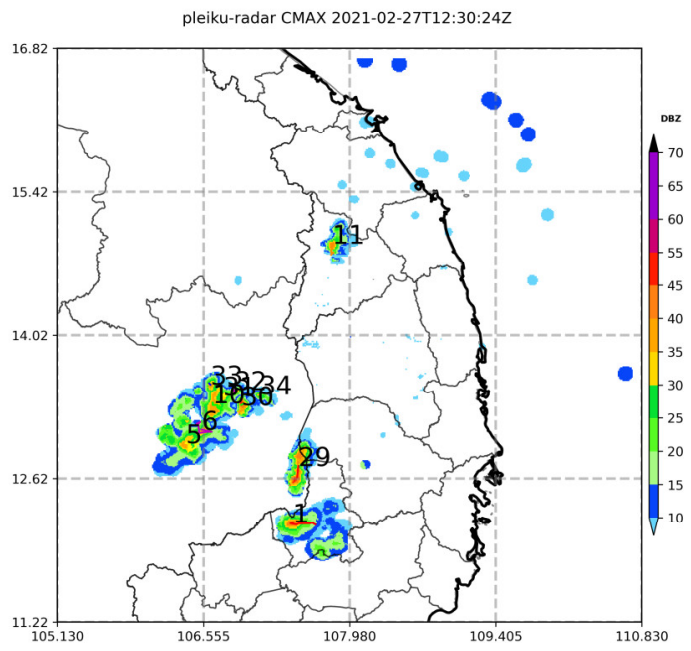

k. $12 \mathrm{~h} 30 \mathrm{UTC}$

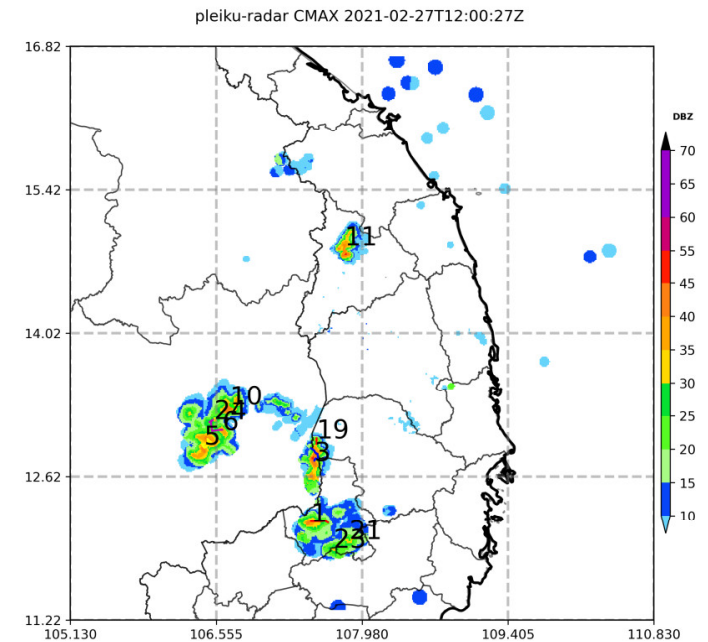

h. $12 \mathrm{~h} 00 \mathrm{UTC}$

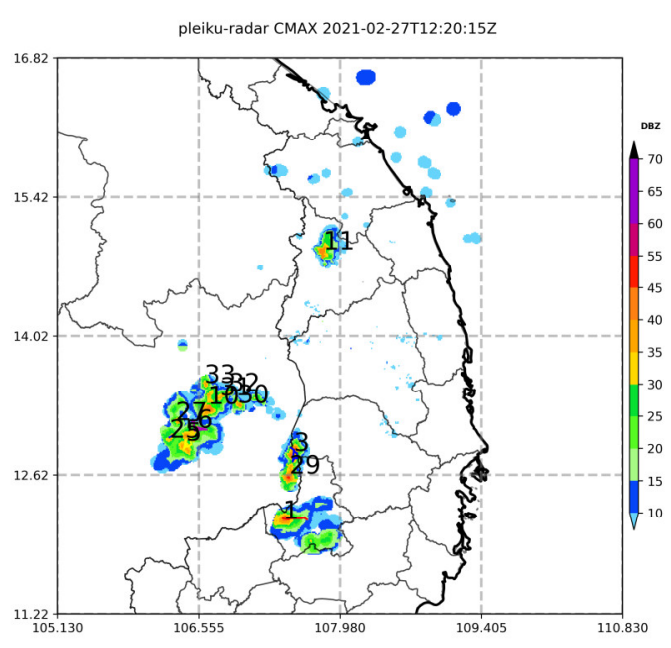

j. $\quad 12 \mathrm{~h} 20 \mathrm{UTC}$

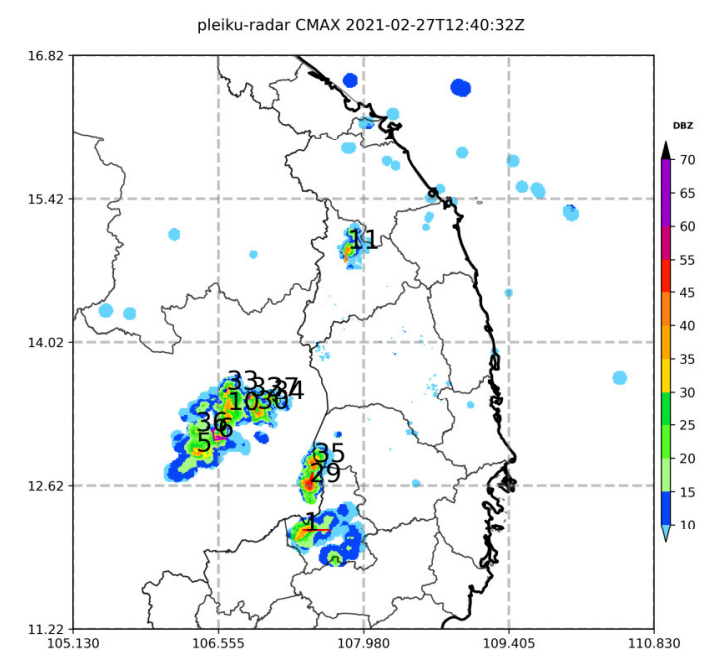

1. $12 \mathrm{~h} 40 \mathrm{UTC}$ 


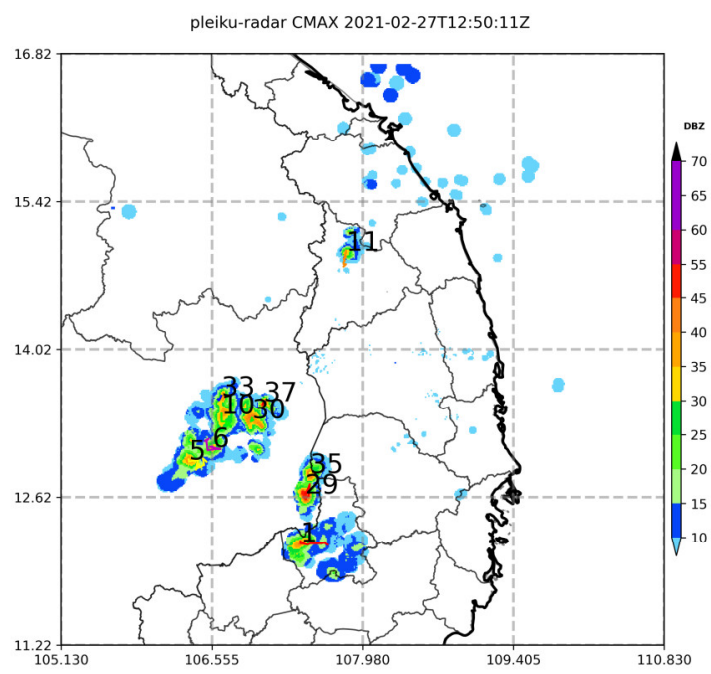

m. $12 \mathrm{~h} 50 \mathrm{UTC}$

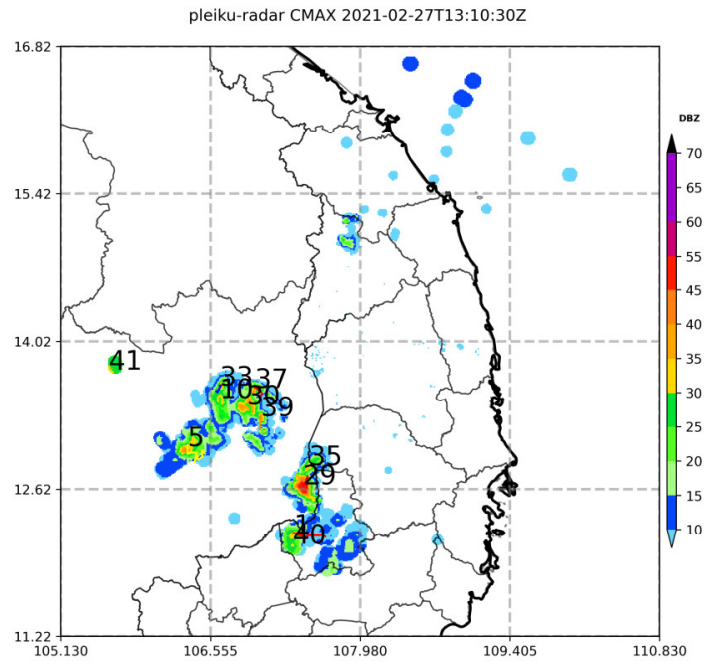

o. $13 \mathrm{~h} 10 \mathrm{UTC}$

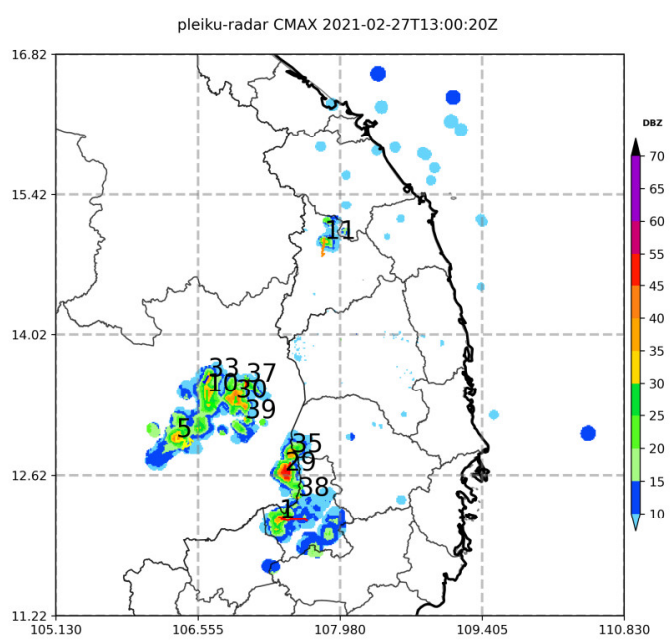

n. $\quad 13 \mathrm{~h} 00 \mathrm{UTC}$

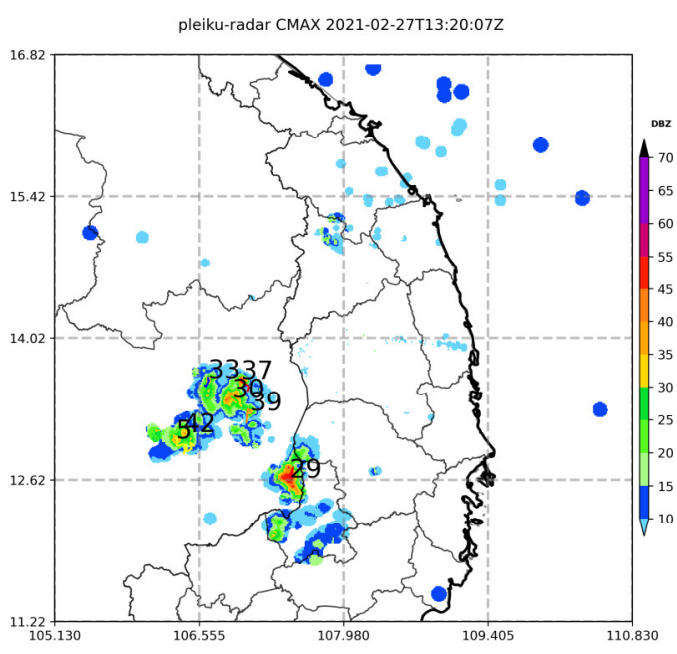

p. $13 \mathrm{~h} 20 \mathrm{UTC}$

Hình 3. Theo dõi quỹ đạo dông từ 11h50 (UTC) đến 13h20 (UTC) ngày 27/2/2021.

Nếu chỉ xét các ổ mây dông trên khu vực lãnh thổ Việt Nam thì Hình 2 cho thấy tại thời điểm 10h50 UTC (tức 17h50 giờ Việt Nam) xác định được 11 ổ mây dông phát triển rải rác ở khu vực tỉnh Kon Tum, Đăk Nông, Đăk Lăk và biên giới Campuchia - Gia Lai, ổ mây dông ở tỉnh Đăk Nông là các ổ dông đa ổ (2 ổ) di chuyển chậm theo hướng Tây Tây Nam, ổ mây dông ở tỉnh Kon Tum là ổ dông đơn ổ có xu hướng phát triển tại chỗ và ít dịch chuyển. Tại thời điểm 11 h00 UTC nhận thấy ổ dông tại tỉnh Kon Tum phát triển mạnh hơn với lõi phản hồi vô tuyến được tăng cường thêm rộng hơn; ổ dông đa ổ tại khu vực tỉnh Kon Tum cũng mạnh lên và được tách thành 2 ổ riêng rẽ với số hiệu là 0 và 1 .

Tiếp tục tập trung phân tích các ổ mây dông 0,1 và 11 tại các thời điểm tiếp theo nhận thấy ổ mây dông 11 tại khu vực tỉnh Kon Tum tiếp tục phát triển mạnh hơn trở thành dông đa ổ (4 ổ) lúc 11 h10 UTC. Ổ dông số hiệu 11 này tiếp tục phát triển và dịch chuyển theo hướng Đông Bắc gây mưa rào và dông cho tỉnh này, sau đó lúc $11 \mathrm{~h} 40$ UTC chúng có dấu hiệu tách ổ thành 2 đám dông có số hiệu là 11 và 20 , lõi ổ dông số hiệu 20 và 22 có thời gian tồn tại ít và sau đó tan rã tại thời điểm $12 \mathrm{~h} 00 \mathrm{UTC}$, còn ổ dông số 11 tiếp tục di chuyển và tồn tại thêm tới thời điểm 13 h00 UTC mới tan rã. Như vậy với các ổ mây dông mạnh, đơn ổ thường có thời gian tồn tại khoảng 1-3 giờ thì chương trình theo dõi quỹ đạo di chuyển của vùng mưa dông nắm bắt được khá tốt. 
Ở các thời điểm tiếp theo ổ dông mang số hiệu 0 và 1 vẫn tồn tại, mở rộng, phát triển mạnh hơn và có xu hướng dịch chuyển chậm hơn theo hướng Tây Tây Nam cho đến 13h20 UTC mới có dấu hiệu suy yếu và tan rã. Các ổ mây dông này đã gây mưa rào và dông mạnh cho các huyện Tuy Đức, Đăk Song, thành phố Gia Nghĩa với lượng mưa phổ biến 35-55 mm/3h (16h00 UTC - 19h00UTC). Tại thời điểm 11h20 UTC có nhiều ổ dông nhỏ có lõi phản hồi vô tuyến mạnh hơn $35 \mathrm{dBZ}$ được xác định là các ổ dông mới hình thành mang số hiệu 15 và 16 , nhưng chỉ 10 phút sau chúng đã yếu đi và tan rã. Đến thời điểm 11 h40 UTC các ổ dông khác tại khu vực tỉnh Đăk Nông đã suy yếu và chỉ còn ổ dông mang số hiệu 1 là tồn tại, đến $12 \mathrm{~h} 00$ UTC vùng dông 1 này tách ra thành 2 đám dông 21 và 23 , sau đó nhanh chóng suy yếu. Vùng lõi dông mạnh của vùng dông 1 vẫn tiếp tục tồn tại với cường độ phản hồi vô tuyến yếu hơn so với các thời điểm trước, sau đó đến khoảng $13 \mathrm{~h} 10$ UTC thì tan rã. Trong trường hợp ổ dông 1 này thì vòng đời tồn tại của nó cũng trong khoảng gần 3 giờ, trong quá trình đó cũng xảy ra sự tách và nhập dông, sự phát triển và suy yếu trong chính lõi của ổ mây dông này. Chương trình theo dõi quỹ đạo ổ mây dông cũng nắm bắt được xu thế dịch chuyển cũng như sự nhập, tách và đã hiệu chỉnh để tăng số lượng đám dông trong quá trình theo dõi.

Trong trường hợp thử nghiệm thứ hai ngày $27 / 2 / 2021$, kết quả ban đầu cho thấy rằng chương trình theo dõi ổ mây dông trong nghiên cứu này xây dựng đã bắt được xu hướng dịch chuyển, quỹ đạo của các vùng mây dông từ khi xuất hiện đến khi tan rã, rõ ràng nhận diện được dấu hiệu tan rã cũng như phát triển của từng vùng mây dông riêng rẽ. Chương trình cũng thể hiện rõ tính khả thi khi theo dõi các ổ dông phát triển cục bộ có kích thước nhỏ, không mang tính hệ thống, tồn tại trong thời gian từ 1 đến 3 giờ.

\section{Kết luận}

Nghiên cứu đã trình bày về phương pháp theo dõi quỹ đạo các ổ mây dông được phát triển dựa trên thuật toán của phần mềm TITAN. Các ngưỡng được đưa ra để xác định và khoanh vùng khu vực các ổ mây dông gồm các thông số là: FIELD_THRESH, ISO_THRESH, ISO_SMOOTH, MIN_SIZE, SEARCH_MARGIN, FLOW_MARGIN, MAX DISPARITY, MAX FLOW MAG, MAX SHIFT DISP và GS ALT.

Chương trình theo dõi ổ mây dông được áp dụng thử nghiệm để theo dõi quỹ đạo vùng mưa dông phát triển cục bộ gây ra mưa rào và dông mạnh cho khu vực Đăk Nông và Kon Tum vào ngày $27 / 2 / 2020$ và trường hợp mưa dông ngày 23/9/2020 gây ảnh hưởng chủ yếu các tỉnh thuộc khu vực Tây Bắc nước ta. Dữ liệu ở hai trạm ra đa thời tiết Pleiku và Pha Đin được lựa chọn để tính toán tại các thời điểm thích hợp tương ứng với 2 trường hợp trên. Các ngưỡng được thiết lập phát hiện dông là $35 \mathrm{dBZ}$ và có diện tích là từ 20 pixel trở lên. Chương trình đơn giản, dễ cài đặt, dễ sử dụng, không yêu cầu phải thiết lập đầu vào dữ liệu ra đa theo các luồng xử lý dữ liệu mặc định như phần mềm TITAN. Chương trình được viết để xử lý tất cả dữ liệu ra đa của Việt Nam, có thể sử dụng cho riêng từng loại ra đa hoặc sử dụng cho mạng lưới tổ hợp các ra đa của Việt Nam do đó chương trình được xây dựng trên thuật toán đề cập trong nghiên cứu này linh hoạt và tiện lợi hơn phần mềm TITAN là thường chỉ áp dụng được với từng hệ thống ra đa riêng lẻ.

Một số kết quả nghiên cứu ban đầu cho thấy rằng thuật toán theo dõi quỹ đạo di chuyển của vùng mưa dông được đề cập ở trên là tương đối phù hợp, đã bắt được xu hướng dịch chuyển của các vùng mây, quỹ đạo từ khi xuất hiện đến khi tan rã của vùng mây. Tuy nhiên số lượng cơn dông tăng lên khá nhanh nếu ngưỡng PHVT được chọn là thấp và có vẻ như thuật toán phù hợp hơn trong việc theo dõi các ổ dông đơn lẻ, phát triển cục bộ. Bài báo mới chỉ dừng lại ở việc theo dõi sự di chuyển của các ổ mây dông, chưa tập trung nghiên cứu sâu vào cơ chế phát triển của từng ổ mây dông nguy hiểm. Do đó cần phát triển đồng bộ thêm với chương trình theo dõi ổ mây dông là các nghiên cứu về mặt cắt gần thẳng đứng để phân tích chi tiết hoá quá trình vi vật lý mây của từng đám mây, từ đó dự báo sự phát triển, di chuyển của từng ổ mây dông. 
Đóng góp của tác giả: Xây dựng ý tưởng nghiên cứu: B.T.K.H.; Lựa chọn phương pháp nghiên cứu: B.T.K.H, N.V.T., P.K.Q.; Xử lý số liệu: N.V.H.; Phân tích mẫu: B.T.K.H, N.V.H., N.T.H.A., P.K.Q.; Lấy mẫu: B.T.K.H., N.V.H. Viết bản thảo bài báo: B.T.K.H, N.T.H.A.; Chỉnh sửa bài báo: B.T.K.H, N.T.H.A.

Lời cảm ơn: Tập thể tác giả trân trọng cảm ơn sự hỗ trợ của đề tài nghiên cứu khoa học cấp Bộ "Nghiên cứu xây dựng công cụ cảnh báo dông và định lượng mưa cho các khu vực ở Việt Nam trên cơ cở sử dụng số liệu ra đa thời tiết, định vị sét, ảnh mây vệ tinh Himawari và mưa bề mặt", mã số TNMT.2018.05.18.

Lò̀i cam đoan: Tập thể tác giả cam đoan bài báo này là công trình nghiên cứu của tập thể tác giả, chưa được công bố ở đâu, không sao chép từ những nghiên cứu trước đây; không có sự tranh chấp lợi ích trong nhóm tác giả.

\section{Tài liệu tham khảo}

1. Dixon, M.; Wiener, G. TITAN: Thunderstorm identification, tracking, analysis, and nowcasting - A radar-based methodology. J. Atmos. Ocean. Technol. 1993, 10, $785-797$.

2. Dixon, M. Titan: Workshop on Techniques for Convective Storm Nowcasting. 2011. https://slideplayer.com/slide/9372394/.

3. Han, L.; Fu, S.X.; Yang, G., Wang, H.Q.; Zheng, Y.G.; Lin, Y.J. A stochastic method for convective storm identification, tracking and nowcasting. Prog. Nat. Sci. 2008, 18, 1557-1563.

4. Han, L.; Fu, S.; Zhao, L.; Zheng, Y.; Wang, H.; Lin, Y. 3D convective storm identification, tracking, and forecasting - An enhanced TITAN algorithm. J. Atmos. Ocean. Technol. 2009, 26, 719-732.

5. Johnson, J.; Mac Keen, P.; Witt, A.; Mitchell, E.; Stumpf, G.; Eilts, M.; Thomas, $\mathrm{K}$. The storm cell identification and tracking algorithm: An enhanced WSR-88D algorithm. Weather Forecasting 1998, 13, 263-276.

6. Kessinger, C.; Hondl, K.; Rabin, R. An efficient, general-purpose technique for identifying storm cells in geospatial images. J. Atmos. Oceanic Technol. 2009, 26, 523-537.

7. Lakshmanan, V.; Hondl, K.; Rabin, R. An efficient, general-purpose technique for identifying storm cells in geospatial images. J. Atmos. Oceanic Technol. 2009, 26, 523-537.

8. Liu, X. The short-time forecasting and nowcasting technology of severe convective weather for aviation meteorological services in China. 2017. https://library.wmo.int/doc_num.php?explnum_id $=4420$.

9. Rinehart, R.E.; Garvey, E.T. Three-dimensional storm motion detection by conventional weather radar. Nat. 1978, 273, 287-289.

10. Trapp, J.; Tessendorf, S.; Godfrey, E.; Brooks, H. Tornadoes from squall lines and bow echoes. Part I: Climatological distribution. Weather Forecasting 2005, 20, 23-34.

11. Thanh, C.; Nguyên, V.T.; Thức, T.D. Úng dụng phần mềm Titan để nhận dạng, theo dõi, phân tích tức thời ô dông cho khu vực Thành phố Hồ Chí Minh. Tạp chí Khoa học Đại học Quốc gia Hà Nội, Các Khoa học Trái đất và Môi trương 2018, 34(1S), $18-25$. 


\title{
An experimental study on thunderstorm tracking using weather radar data in Vietnam
}

\section{Bui Thi Khanh Hoa $^{1 *}$, Nguyen Vinh Thu ${ }^{1}$, Phung Kien Quoc ${ }^{1}$, Nguyen Viet Hung ${ }^{1}$, Nguyen Thi Hoang Anh ${ }^{1}$}

${ }^{1}$ Aero Meteorological Observatory; khanhhoa303@gmail.com; vinhthu73@gmail.com; kienquocamo@gmail.com; nguyenviethungb115@gmail.com; hoanganhck@gmail.com

\begin{abstract}
Weather radar is an effective monitoring tool for tracking, detecting, and nowcasting the movement of convection cloud areas that can cause dangerous weather phenomena. This paper introduces the new method for thunderstorm tracking based on TITAN software "Thunderstorm identification, tracking, analysis and nowcasting" using the weather radar reflectivity in Vietnam. The experimental study is applied to the case of thunderstorms that affected mainly the Northwest Region on September 23 ${ }^{\text {rd }}, 2020$ and the the case of thunderstorms that affected Kon Tum and Dak Nong provinces on February $27^{\text {th }}$, 2021. The results showed that the developed algorithm for thunderstorm tracking can catch the movement of the cloud areas from the developing stage to the dissipating stage. That algorithm, however, seems to be better for single-cell thunderstorm tracking.
\end{abstract}

Keywords: Thunderstorm; Weather radar; Tracking. 